\title{
The Journal of Molecular Evolution Turns 50
}

\author{
Aaron D. Goldman ${ }^{1,2} \cdot$ David A. Liberles $^{3}$ \\ Accepted: 4 February 2021 / Published online: 23 February 2021 \\ (c) The Author(s), under exclusive licence to Springer Science+Business Media, LLC part of Springer Nature 2021
}

Molecular evolution as a distinct discipline began to take shape in the 1960s as insights from biochemistry and population genetics combined with the emerging field of molecular biology, which offered new tools for comparing biomolecules and their sequences across evolutionary distance. Two early achievements, the establishment of molecular clocks and the subsequent development of the neutral theory, laid the foundation for molecular evolution (Suárez-Díaz 2016). Following on these accomplishments, the Journal of Molecular Evolution was founded and its first issue was published 50 years ago this month (see Liberles 2019). In this special issue, we celebrate the history of this journal and the field that it chronicled over the last half century.

Just as molecular evolution emerged from the techniques and insights of molecular biology, biological chemistry, and population genetics, the field has kept pace through monumental changes in the life sciences, as advances in molecular biology have brought about the new paradigms of genomics, bioinformatics, and systems biology. In the last 50 years, molecular evolution has given us a clearer understanding of evolutionary history, evolutionary processes, and the diversity of the biosphere. As the first journal dedicated to molecular evolution, the Journal of Molecular Evolution has published many seminal articles throughout the field's history.

In this special 50th anniversary issue, we highlight some of the most important studies that were published over the journal's history. This sampling of topics reflects the choices

Aaron D. Goldman

agoldman@oberlin.edu

$\triangle$ David A. Liberles

daliberles@temple.edu

1 Department of Biology, Oberlin College and Conservatory, Oberlin, OH 44074, USA

2 Blue Marble Space Institute of Science, Seattle, WA 98154 , USA

3 Department of Biology and Center for Computational Genetics and Genomics, Temple University, Philadelphia, PA 19122, USA of individual editors and is necessarily non-exhaustive. We invited current members of the editorial board to each choose an article from the journal archive that has had a substantial impact on their respective discipline and write a perspective piece summarizing the article, its scientific context, the subsequent research that it motivated since its publication, and their perspective on future directions in that area. We present 10 such articles in this issue, which span a broad range of topics within molecular evolution.

- The structures of cytochrome $\mathrm{c}$ and the rates of molecular evolution (Dickerson 1971)

- Coenzymes as fossils of an earlier metabolic state (White 1976)

- Evolutionary trees from DNA sequences: A maximum likelihood approach (Felsenstein 1981)

- Dating of the human-ape splitting by a molecular clock of mitochondrial DNA (HKY85) (Hasegawa et al. 1985)

- Plant mitochondrial DNA evolves rapidly in structure, but slowly in sequence (Palmer and Herbon 1988)

- Probabilistic reconstruction of ancestral protein sequences (Koshi and Goldstein 1996)

- Relationships Between Genomic G + C Content, RNA Secondary Structures, and Optimal Growth Temperature in Prokaryotes (Galtier and Lobry 1997)

- Exploring Nonnatural Evolutionary Pathways by Saturation Mutagenesis: Rapid Improvement of Protein Function (Miyazaki and Arnold 1999)

- On the Origin of Metabolic Pathways (Lazcano and Miller 1999)

- On the Possibility of Constructive Neutral Evolution (Stoltzfus 1999)

These articles highlight many of the historical strengths of the journal. With its founding editor, Emile Zuckerkandl, there was an early emphasis on methods for better understanding molecular evolutionary history and processes (Lehman 2013; Liberles 2019). Dr. Zuckerkandl is most well known for his development of molecular clocks along with his postdoctoral supervisor, Linus Pauling, himself a 
founding editorial board member. Early seminal articles published in the journal expand on the topic of molecular clocks (Hasegawa et al. 1985 (commentary by Zardoya 2021)) as well as the related subjects of neutral evolution in the idea of constructive neutralism (Stoltzfus 1999) and evolutionary rates (Dickerson 1971 (commentary by Alvarez-Ponce 2021); Palmer and Herbon 1988 (commentary by Christensen 2021)).

As the first journal dedicated to the study of molecular evolution, the journal also published major advances in phylogenetic methods (Felsenstein 1981 (commentary by Posada and Crandall 2021); Hasegawa et al. 1985 (commentary by Zardoya 2021)) that draw upon model-based substitution processes and evolutionary rates. This was used by Felsenstein, for example, in the development of maximum likelihood methods on top of a new evolutionary rate model (Felsenstein 1981 (commentary by Posada and Crandall 2021)). Further, substitution models can be used for ancestral sequence reconstruction. One of the first algorithms for maximum likelihood ancestral protein sequence reconstruction was published in the journal (Koshi and Goldstein 1996 (commentary by Selberg et al. 2021)).

The journal also maintained a focus on chemical and biochemical evolution, leading to its publication of seminal studies on evolutionary mechanisms (Galtier and Lobry 1997 (commentary by Meyer 2021) including constructive neutralism (Stoltzfus 1999 (commentary by MuñozGómez et al. 2021)), and the interplay between evolutionary processes, biophysical processes, and experimental tools (Miyazaki and Arnold 1999 (commentary by Voskarides, 2021)). With the inclusion of chemical evolution in its purview, the Journal of Molecular Evolution has also retained a tradition in publishing key studies about the origin and early evolution of life (White 1976 (commentary by Goldman and Kacar 2021); Lazcano and Miller 1999 (commentary by Becerra 2021)), a subfield at the interface of biology and chemistry.

Of course, all of these early articles predate the incredible paradigm shift that all life sciences have undergone over the last two decades thanks to genomics, bioinformatics, computational biology, and systems biology. As the field of molecular evolution expanded to integrate high throughput biological data with an understanding of the processes that generate them, so too has the scope of the journal (Liberles et al. 2020). Since the field of molecular evolution began roughly six decades ago, this deeper understanding of molecular-level evolutionary mechanisms and processes, along with the tools to measure them, have become indispensable parts of all biomedical and life sciences.

While the articles in this 50th anniversary edition celebrate a selection of the past achievements published in the journal, they also describe the subsequent research that they have motivated since its publication and the future research that they are likely to inspire. As documented here, molecular evolution has had a storied history. It will also undoubtedly have a far reaching and consequential future, where it now more than ever lies at the center of modern biology.

\section{References}

Alvarez-Ponce D (2021) Richard Dickerson, molecular clocks, and rates of protein evolution. J Mol Evol. https://doi.org/10.1007/ s00239-020-09973-x

Becerra A (2021) The semi-enzymatic origin of metabolic pathways: inferring a very early stage of the evolution of life. J Mol Evol. https://doi.org/10.1007/s00239-021-09994-0

Christensen A (2021) Plant mitochondria are a riddle wrapped in a mystery inside an enigma. J Mol Evol. https://doi.org/10.1007/ s00239-020-09980-y

Dickerson RE (1971) The structures of cytochrome $\mathrm{c}$ and the rates of molecular evolution. J Mol Evol 1:26-45. https://doi.org/10.1007/ BF01659392

Felsenstein J (1981) Evolutionary trees from DNA sequences: a maximum likelihood approach. J Mol Evol 17:368-376. https://doi. org/10.1007/BF01734359

Galtier N, Lobry JR (1997) Relationships between genomic G+C content, RNA secondary structures, and optimal growth temperature in prokaryotes. J Mol Evol 44:632-636. https://doi.org/10.1007/ p100006186

Goldman AD, Kacar B (2021) Cofactors are remnants of life's origin and early evolution. J Mol Evol. https://doi.org/10.1007/s0023 9-020-09988-4

Hasegawa M, Kishino H, Yano T (1985) Dating of the human-ape splitting by a molecular clock of mitochondrial DNA. J Mol Evol 22:160-174. https://doi.org/10.1007/BF02101694

Koshi JM, Goldstein RA (1996) Probabilistic reconstruction of ancestral protein sequences. J Mol Evol 42:313-320. https://doi. org/10.1007/BF02198858

Lazcano A, Miller SL (1999) On the origin of metabolic pathways. J Mol Evol 49:424-431

Lehman N (2013) Editorial changes at the Journal of Molecular Evolution. J Mol Evol 76:1-3. https://doi.org/10.1007/s0023 9-013-9546-3

Liberles DA (2019) A new editorial beginning at journal of molecular evolution. J Mol Evol 87:69-71. https://doi.org/10.1007/s0023 9-019-09888-2

Liberles DA, Chang B, Geiler-Samerotte K, Goldman A, Hey J, Kaçar B, Meyer M, Murphy W, Posada D, Storfer A (2020) Emerging frontiers in the study of molecular evolution. J Mol Evol 88:211226. https://doi.org/10.1007/s00239-020-09932-6

Meyer MM (2021) Revisiting the relationships between genomic $\mathrm{G}+\mathrm{C}$ content, RNA secondary structures, and optimal growth temperature. J Mol Evol. https://doi.org/10.1007/s00239-020-09974-w

Miyazaki K, Arnold FH (1999) Exploring nonnatural evolutionary pathways by saturation mutagenesis: rapid improvement of protein function. J Mol Evol 49:716-720. https://doi.org/10.1007/ p100006593

Muñoz-Gómez SA, Bilolikar G, Wideman JG, Geiler-Samerotte K (2021) Constructive neutral evolution 20 years later. J Mol Evol. https://doi.org/10.1007/s00239-021-09996-y

Palmer JD, Herbon LA (1988) Plant mitochondrial DNA evolves rapidly in structure, but slowly in sequence. J Mol Evol 28:87-97. https://doi.org/10.1007/BF02143500

Posada D, Crandall KA (2021) Felsenstein phylogenetic likelihood. J Mol Evol. https://doi.org/10.1007/s00239-020-09982-w 
Selberg AGA, Gaucher EA, Liberles DA (2021) Ancestral sequence reconstruction: from chemical paleogenetics to maximum likelihood algorithms and beyond. J Mol Evol. https://doi.org/10.1007/ s00239-021-09993-1

Stoltzfus A (1999) On the possibility of constructive neutral evolution. J Mol Evol 49:169-181. https://doi.org/10.1007/pl00006540

Suárez-Díaz E (2016) Molecular evolution in historical perspective. J Mol Evol 83:204-213
Voskarides K (2021) Directed evolution. The legacy of a nobel prize. J Mol Evol. https://doi.org/10.1007/s00239-020-09972-y

White HB 3rd (1976) Coenzymes as fossils of an earlier metabolic state. J Mol Evol 7:101-104. https://doi.org/10.1007/BF01732468

Zardoya R (2021) Quest for the best evolutionary model. J Mol Evol. https://doi.org/10.1007/s00239-020-09971-z 